(b) that the assessment of professional remuneration shall be $a b$ initio; (c) that the basis can be applied to alternative methods of remuneration-e.g., capitation fee, item of service, some form of salary ; $(d)$ that this particular reference will neither be restricted by the criteria established by the Royal Commission nor prejudiced by the considerations expressed in paragraphs 42 and 46 of the Review Body's fifth report."

Paragraph 42 of the fifth report ${ }^{3}$ stressed that the Review Body would take into consideration earnings from all sources as being relevant to their determination of what a doctor should earn in the N.H.S. Paragraph 46 expressed disagreement with the profession's view that the payment of general practitioners had been seriously inadequate since 1948. On the question of pay, the Charter emphasized that it must be related " directly and realistically" to the doctor's work load and responsibility in providing general medical services. "All other services provided by family doctors," the Charter stated, "will be paid for additionally. . . ." These demands undoubtedly have the support of nearly all general practitioners. They have repeatedly said they want to be rid of a Pool system of payment based on what the average doctor should earn from all sources.

It is now for the profession to say whether it is satisfied with the result of the negotiations. The report, printed in full in the Supplement, will be closely examined for the hoped-for assurances. The Conference of Representatives of Local Medical Committees meets on 16-17 June and the Representative Body on 23 June. Each meeting will independently have to decide whether negotiations are to continue or whether they should be brought to an end and the resignations of general practitioners (which have now reached the remarkable number of 17,875) handed in on 1 July to take effect on 1 October. Both the Council and the G.M.S. Committee recommend that negotiations should continue and that resignations should not be handed in. Should the meetings agree to negotiations continuing, a less crucial decision will have to be made on whether resignations should still be held while negotiations go on. The opinions of the Council and of the G.M.S. Committee conflict on this point. As the reports in the Supplement of their meetings last week record, the G.M.S. Committee resolved by 15 votes to 7 to recommend that existing resignations should now be destroyed, while the Council, by 37 votes to 5 , resolved to recommend that the resignations should be kept in hand. If this conflict of opinion is perpetuated by the voting in the Representative Body and in the Conference, each of them autonomous bodies, there could be a constitutional muddle of a kind that would convince even the most dilatory that the time for putting the profession's medico-political representative machinery in order is long overdue.

It seems likely that both the Conference and the Representative Meeting will agree that resignation from the N.H.S. at this juncture would be a mistake. Reasonable if not altogether satisfactory progress has been made on the first three of the matters on which assurances were sought. Those who value the independent status of general practitioners will view with some suspicion the references in the joint report to the need for Governmental control over the general practice finance corporation. The statement that "the Health Ministers would need to have powers to issue directions to

\footnotetext{
Brit. med. F. Suppl., 1965, 1, 113.

Ibid., 1965, 1, 89.

- Review Body on Doctors' and Dentists' Remuneration, Third, Fourth, and Fifth Reports, 1965, Cmnd. 2585. London, H.M.S.O.
}

the Corporation" requires further explanation before it can be accepted as innocuous. Again, the Health Ministers are to decide whether practice premises are suitably sited and of a suitable standard before the Corporation provides money for their improvement. The Health Ministers would give " directions on priorities," and, through a central committee, advise on policy. These things have in them the seeds from which can grow too much central direction of developments in general practice. Many doctors will be disappointed that direct reimbursement of the whole cost of ancillary help is ruled out. But if they accept that full reimbursement would entail the sort of controls envisaged they may well conclude that what is proposed is preferable. Similarly, though some will regret that doctors' wives are to be excluded from the scheme for paying for ancillary help, it would seem that irksome conditions might have to be imposed if they were included. There would be nothing to prevent a doctor claiming, as now, income-tax relief on a reasonable payment to his wife for her help in the practice. The proposals for reducing the amount of certification are a victory for common sense. It seems odd that it should have needed a crisis to bring it about.

The major doubts about the strength of the Minister's assurances will centre on the question of pricing the new contract. Readers of the reports of the meetings of the Council and of the G.M.S. Committee will appreciate the difficulties the profession's representatives were faced with in this. The Review Body is independent. Conditions cannot be imposed upon it. It was for that more than for any other reason that the profession welcomed it when it was set up. The Minister's view is clearly stated in paragraph 34 (ii) of the report: " . . . the Government would not think it right to impose on [the Review Body] a requirement to price the contract in a particular way." Clearly this does not amount to the positive and unequivocal assurance wanted. It is a situation which demonstrates the essential dilemma of a profession that has surrendered its right to fix its own fees. Changes that will ease the burden of work in general practice will not satisfy general practitioners as a whole unless a fairly substantial improvement in their economic status is secured at the same time. The crux of the general practitioner's discontent is that his economic status in society has gone down. He wants it to go up-and with reason.

The current negotiations are only a beginning. The terms of the general practitioners' new contract as well as many other parts of the Charter highly relevant to the future have yet to be agreed with the Minister. In making up their minds on the immediate issues before them doctors will be acutely aware that much more is at stake than the mere achievement of an ephemeral victory in a passing dispute. The prize to be competed for is a Health Service in which general practitioners can practise modern medicine to their satisfaction and that of the community they serve. Nothing less will do. To borrow a phrase from Dr. Cameron, which all will echo, "It is important to get this right." If negotiations continue there is a chance of getting things right.

\section{Respiratory Failure}

The function of the lungs is to exchange gas between inspired air and the blood passing through them. It is therefore logical to look for evidence of failure of lung function in the systemic arterial blood. Respiratory failure may best be defined as that state, due to disordered function 
of the lungs, in which there is a substantial decrease of the partial pressure of oxygen in the arterial blood, with or without a substantial increase of the partial pressure of carbon dioxide. This condition may be acute or chronic, but an acute exacerbation superimposed on chronic failure is how the patient most often presents with it.

Recognition of the problem has grown in recent years largely owing to the efforts of physician-physiologists who have brought their special knowledge to the bedside. It is nevertheless true that the care of many patients with respiratory failure could still be improved, and it will be if the underlying physiological principles are understood more widely. Many readers will therefore welcome the review of the subject given by Dr. Moran Campbell (who has himself contributed notably to its advancement) in the Goulstonian lecture published at page 1451 of the B.M.F. this week.

It is an everyday experience of clinical practice that half the battle in reaching a diagnosis is being aware of its possibility in the first place. This is especially true of respiratory failure, for it has a multiplicity of causes and so must be borne in mind in all sorts of different circumstances. It may occur from lesions in the chest wall, such as those of neuromuscular disorders, chest injuries, or abdominal and thoracic operations. Intracranial lesions of the central nervous system comprise another group of causes. And a third group includes diseases of the hung itself, the commonest of which is chronic bronchitis. Physical signs in respiratory failure are of little value in diagnosis. "Central" cyanosis-that is, a blue colour of the mucous membranes despite a high blood-flowis unreliable in that profound and dangerous hypoxaemia may be present before the sign is unequivocally evident. Mental clouding, confusion, and a flapping tremor of the hands are often seen in association with an increase of the partial pressure of carbon dioxide in the arterial blood, but are not sufficiently consistent to be diagnostic.

Whenever the clinical situation points to the possibility of respiratory failure the partial pressures of oxygen and carbon dioxide in the arterial blood should be assessed without delay. Since a very large proportion of these patients have a raised partial pressure of carbon dioxide $\left(\mathrm{PCO}_{2}\right)$, this should be the first measurement to be made. The rebreathing technique of Moran Campbell and J. B. L. Howell ${ }^{1}$ allows the $\mathrm{PCO}_{2}$ to be measured indirectly. Some investigators have found, especially when dealing with very ill patients, that the method is not very precise, though it is usually sufficiently reliable to indicate when the $\mathrm{PCO}_{2}$ is greatly increased. A preferable procedure is the Astrup micro-method, ${ }^{2}$ which is now widely available. The blood should for preference be taken from an ear lobe in which vasodilatation has been induced, since false results may be obtained if the sample comes from a finger tip, in which the blood-vessels are subject to peripheral vasoconstriction. The Astrup method has the additional advantage that it also estimates $p \mathrm{H}$ and standard bicarbonate, from which it is possible to deduce something of the history of the respiratory failure-whether it is of acute onset or represents an exacerbation of a chronic state.

The danger to the patient in respiratory failure is rather from the low oxygen in the blood than from the frequently

\footnotetext{
1 Campbell, E. J. M., and Howell, J. B. L., Brit. med. f., 1962, 2, 630. 2 Astrup, P., Jorgensen, K., Siggaard Anderson, O., and Engel, K., Lancet, 1960, 1, 1035 .

Wright, B. M., ibid., 1958, 2, 24.

- Christie, R. V., Respiratory Failure: The Frederick Price Lecture for 1963. Royal College of Physicians, Edinburgh. 1964
}

co-existent high partial pressure of carbon dioxide. Treatment should therefore be directed to correcting the hypoxaemia by giving oxygen and by improving the volume and the distribution of alveolar ventilation. The patient should breathe continuously fully humidified, oxygen-enriched air, the concentration of oxygen being such as to raise the $\mathrm{Po}_{2}$ in the arterial blood to $50 \mathrm{~mm}$. $\mathrm{Hg}$ or more, which corresponds to an oxygen saturation in the blood of about $80 \%$. The equipment should be comfortable and acceptable to the patient, since he must wear it for many hours, and should leave him readily accessible for nursing procedures and for clinical observation. The administration of oxygen causes a rise at first of the partial pressure of carbon dioxide in the blood, and if it is uncontrolled it may lead to progressive neurological and mental deterioration and ultimately to coma. Fear of such an outcome should never lead to the withholding of oxygen, but the concentration of oxygen should be regulated in the light of this knowledge. The correct concentration is the lowest which will raise the $\mathrm{Po}_{2}$ to the safe level of $50 \mathrm{~mm} . \mathrm{Hg}$, and is usually around $30 \% \mathrm{O}_{2}$ in the inspired air. Patients vary so much, however, that it is advisable if possible to make serial measurements of both arterial $\mathrm{Po}_{2}$ and $\mathrm{PCO}_{2}$, and to adjust the concentration of inspired oxygen accordingly. It cannot be over-emphasized that oxygen should be accurately prescribed and administered; its use must not be left to the patient's decision or to the attempts of a nurse to interpret vague instructions. The ideal equipment has yet to be designed, and we need to know much more about the performance of available apparatus. For instance, some widely used disposable masks allow a substantial degree of rebreathing, which upsets the precision of the dosage. The administration of the right antibiotics is essential to the treatment of patients with acute or chronic respiratory failure. In addition bronchodilator aerosols, especially of isoprenaline, are helpful if given regularly, under supervision, and with an efficient nebulizer. ${ }^{3}$ The chief purpose of tracheostomy is to enable bronchial secretions to be aspirated if the patient is unable to cough effectively. Its place is less certain in the treatment of a patient grossly disabled before his present illness began, especially in view of the long-term risks it carries of secondary infection. For many of the patients in whom respiratory failure is not due to primary disease of the lung the need for positive pressure-assisted ventilation is the principal indication for tracheostomy.

The management of respiratory failure must be based on physiological principles, and one cannot do better than join with Campbell in quoting R. V. Christie, ${ }^{4}$ who has stated that " death from respiratory failure can almost always be delayed or prevented, provided that the physician or surgeon is aware of the hazards involved and provided that adequate facilities are available."

\section{Recent Mortality}

For the first time the General Register Office has used a computer for the production of its annual review of medical statistics for England and Wales. The result is a volume ${ }^{1}$ which is of larger format, contains more pages, and costs more than its predecessors. Relating to the year 1963, it appears after a somewhat greater delay than has been customary in recent years owing to teething troubles in the 